\title{
Covid-19 e a educação em moçambique: entraves, desafios e possibilidades de reinvenção da educação
}

\author{
Covid-19 and education in mozambique: obstacles, challenges, and \\ possibilities for reinventing education \\ Covid-19 y la educación en mozambique: obstáculos, desafíos y posibilidades \\ para reinventar la educación
}

FERNANDO ANDRE MUZIME

https://orcid.org/0000-0002-4584-0172

Universidade Eduardo Mondlane

Programa de Pós-graduação em Educação

Maputo, Moçambique

OCTAVIO JOSE ZIMBICO

https://orcid.org/0000-0002-7061-1582

Universidade Eduardo Mondlane

Programa de Pós-graduação em Educação

Maputo, Moçambique

\begin{abstract}
Resumo: A pandemia do Covid-19 conveliu a vida pública de uma maneira profunda, colocando grandes desafios no sector da educação, fomentando novas metodologias de ensino vinculadas, principalmente, através de organizações internacionais, no caso da UNESCO. De modo a conter a rápida propagação do coronavírus, Moçambique declarou o Estado de Emergência em nível nacional. Dentre as medidas anunciadas pelo Chefe de Estado, consta a suspensão das aulas em todos os estabelecimentos públicos e privados, desde o ensino pré-escolar até o superior. Portanto, este artigo visa apurar os desafios que a educação enfrenta bem como as possibilidades da sua reinvenção no contexto da pandemia do coronavírus. Metodologicamente, foi privilegiada a pesquisa bibliográfica, com recurso ao materialismo histórico-dialéctico. Os resultados impõem grandes investimentos, sobretudo, de infraestruturas, formação do capital docente em vários níveis de ensino, apropriação dos conhecimentos das TICs e, para tal, aponta-se a necessidade de um Pacto Educativo entre os diferentes extractos sociais e o Estado como alternativa de mitigação e superação da crise no sistema educacional.
\end{abstract}

Palavras-chave: Educação, Pandemia do Covid-19, Pacto Educativo 


\begin{abstract}
The Covid-19 pandemic has profoundly changed public life, posing major challenges in the education sector, fostering new teaching methodologies linked mainly through international organizations, in the case of UNESCO. In order to contain the rapid spread of the coronavirus, Mozambique declared a State of Emergency at the national level. Among the measures announced by the Head of State, there is the suspension of classes in all public and private establishments, from Pre-school to Higher Education. Therefore, this article aims to address the challenges that education faces as well as the possibilities of its reinvention in the context of the coronavirus pandemic. Methodologically, bibliographic research was privileged using historical-dialectical materialism. The results impose large investments, above all, in infrastructures, formation of teaching capital at various levels of education, and appropriation of ICT knowledge. For this, the need for an Educational Pact between the different social strata and the State is pointed out as an alternative to mitigate and overcome the crisis in the educational system.
\end{abstract}

Keywords: Education, Covid-19 Pandemic, Educational Pact.

Resumen: La pandemia Covid-19 dio a conocer profundamente la vida, planteando grandes desafios en el sector educativo, fomentando nuevas metodologías de enseñanza vinculadas principalmente a través de organismos internacionales, en el caso de la UNESCO. Para contener la rápida propagación del coronavirus, Mozambique declaró el estado de emergencia a nivel nacional. Entre las medidas anunciadas por el Jefe de Estado, se encuentra la suspensión de clases en todos los establecimientos públicos y privados, desde el preescolar hasta la educación superior. Por tanto, este artículo tiene como objetivo abordar los retos a los que se enfrenta la educación, así como las posibilidades de su reinvención en el contexto de la pandemia de coronavirus. Metodologicamente, se privilegió la investigación bibliográfica utilizando el materialismo histórico-dialéctico. Los resultados imponen grandes inversiones, sobre todo, en infraestructuras, formación de capital docente en los distintos niveles educativos, apropiación de conocimientos TIC y, para ello, se apunta la necesidad de un Pacto Educativo entre los diferentes estratos sociales y el Estado como alternativa para mitigar y superar la crisis del sistema educativo.

Palabras-clave: Educación, Pandemia Covid-19, Pacto Educativo.

\title{
INTRODUÇÃO
}

A educação é paralela à existência humana. É verdade que ela sofre um processo de recontextualização em cada época histórica de acordo com os problemas sociais, econômicos, políticos, culturais, ideológicos que a caracterizavam. Desde o seu surgimento, a educação sempre foi associada e controlada pela classe dominante e, a história mostra que ela serve de "arma" para a conquista do poder, assim como, para o desenvolvimento social.

Atualmente, a educação enfrenta, sobretudo, dois grandes problemas de dimensão global: (i) políticas neoliberais que desumanizam o perfil do professor, reduzem o papel do Estado na regulação das Políticas Educativas, sobretudo do Ensino Básico, projeto de construção nacional, aliás, o neoliberalismo transforma o carácter social da educação em um campo de reprodução do capital, afetando 
deste modo o Projeto de Construção Nacional; e (ii) a Covid-19, sendo que, devido aos impactos do SARS-CoV-2 em Moçambique, o foco desta pesquisa encontra-se, especificamente, centrado neste segundo problema, ora destacado.

Geograficamente, Moçambique situa-se, no Sudeste do continente africano, na região da África Austral e esteve sob a dominação portuguesa desde 1884/5, depois da Conferência de Berlim, tornando-se independente em 25 de Junho de 1975. Desde esse período, houve entrosamento de políticas internas e externas no territorio moçambicano, o que culminou com a nacionalização do Ensino e da Educação a partir do Decreto no 12/75, de 6 de Setembro. Desde então, o governo de Moçambique apostou na massificação do ensino que só seria viável por meio de formação "acelerada" de professores (BONDE, 2016). Para este autor, essas acções ditavam a proposta do Projecto de Sistema Nacional de Educação (SNE), centrado em três níveis ou subsistemas de ensino (Primário, Secundário e Ensino Superior), que em 1983 marcam uma nova etapa na evolução da Educação em Moçambique. Entretanto, em Maio de 1992, o parlamento aprovou a lei 6/92 de 6 de Maio, sobre o sistema de educação em Moçambique, revogando neste caso a lei 4/83. Com a introdução desta nova lei, o Estado permitiu a participação de outras entidades, incluindo comunitárias, cooperativas, empresariais e privadas, no campo educacional.

Atualmente, a educação experimenta uma nova reforma no Ensino Básico, operacionalizada por meio da revogação da Lei n.o 6/92, de 6 de Maio, pela Lei n.o 18/2018, de 28 de Dezembro, que prevê: a introdução da educação pré-escolar; o ensino primário em seis classes; o ensino bilíngue como modalidade do ensino primário; o Ensino Básico obrigatório e gratuito de nove classes; Ensino Secundário de seis classes; o Ensino à Distância como modalidade de ensino secundário e superior; o perfil de ingresso para a formação dos professores; a educação inclusiva em todos os níveis de ensino e a educação vocacional.

A pandemia do Covid-19 transformou a vida pública de maneira profunda, colocando grandes desafios no sector da educação, fomentando novas metodologias de ensino vinculadas, principalmente, através de organizações internacionais, no caso a UNESCO. É nesse caso, que este artigo visa apurar os desafios que a educação enfrenta bem como as possibilidades da sua reinvenção no contexto da pandemia do coronavírus. Para aferirmos este objetivo contouse com a revisão da literatura, principalmente, dos estudos desenvolvidos por Yan et al (2020), virologista e pesquisadora que fazia parte do governo Chinês no Instituto de Pesquisa em Wuhan, ora refugiada nos EUA, devido à divulgação das manipulações perpetuadas pelo governo chinês, em colaboração com a OMS. 
Entende-se que estudar os desafios impostos pela Covi-19 desafia também de certa forma os pesquisadores a buscarem uma relação de causa e efeito, ou seja, relação sujeito-objecto.

Compreender a relação sujeito-objecto é compreender como o ser humano se relaciona com a natureza, assim como com a vida. Para tal, privilegiouse o uso do método materialista histórico-dialéctico para a realização deste estudo. Este método caracteriza-se pelo movimento do pensamento através da materialidade histórica da vida dos homens em sociedade (PIRES, 1997).

Recorremos ao método materialista histórico-dialéctico para melhor discutirmos os diferentes paradigmas de interpretação da realidade educacional, situada na época da pandemia do Covid-19, caracterizada por diferentes opiniões sobre o surto, impacto, desafios e possibilidades de reinvenção da educação, impostas pela vigência do novo Coronavírus.

\section{A EDUCAÇÃO E O SURTO DA PANDEMIA DO COVID-19}

A educação existe desde a história da existência do homem, mesmo em sociedades onde não havia a instituição escolar, ela não deixou de ocorrer, embora acontecesse em processos diferentes daqueles utilizados pelo sistema escolar (LULUVA, 2009). Isto significa que em Mocambique, sempre houve a educação. Desde a sua genése como instituição de ensino, promovida pela administração colonial, a educação esteve ligada a grandes desafios, não só, na luta pela libertação do jugo colonial, mas também, nos fenômenos políticos, como a Guerra Civil e as Políticas Neoliberais. A educação em Moçambique, antes da pandemia do Coronavírus, já estava em crise devido à influência das políticas neoliberais no sistema educacional, introduzindo, deste modo, a economia do mercado no campo educacional. O neoliberalismo reduz o papel do Estado, controlando o poder econômico através da privatização das instituições.

Desta feita, julgamos que o maior desafio da educação seria a conquista da sua liberdade dos ditames neoliberais. Portanto, o surto do Covid-19 mostrou a necessidade da reforma do sector da educação em vários ângulos de abordagens que sem descartar os seus impactos negativos pode-se também exaltar uma melhoria na administração educacional, se formos a olhar o caso de Moçambique.

Entretanto, no dia 31 de Dezembro de 2019, a China reportou à Organização Mundial da Saúde (OMS) um cluster de pneumonia de etiologia desconhecida em trabalhadores e frequentadores do Mercado Peixe, mariscos vivos e aves na cidade de Wuhan, província de Hubei, na China. A 9 de Janeiro 
de 2020, as autoridades chinesas identificaram um novo vírus da família dos Coronavírus $^{1}$ (2019-nCoV) como agente causador da doença (GOVERNO DE MOÇAMBIQUE, 2020).

Na sequência, em Moçambique, até o dia 31 de Março de 2020, tinham sido registados oito casos, ao fim do primeiro mês do Estado de Emergência. O número de casos evoluiu para 76. Tendo em conta esta evolução, o Estado de Emergência foi prorrogado por três vezes. Até ao dia 29 de Junho de 2020, último dia do Estado de Emergência, o país tinha um cumulativo de 1.748 casos, sendo 1.581 de transmissão local e 167 casos importados, 616 recuperados e 11 óbitos (ASSEMBLEIA DA REPÚBLICA, 2020).

Uma das formas de transmissão do novo Coronavírus é através de gotículas de saliva de pessoa a pessoa. Assim, devido ao seu impacto coadjuvado com a rápida forma de expansão ao nível internacional, a OMS declarou, a 30 de Janeiro de 2020, a doença por Coronavírus como uma Emergência de Saúde Pública de âmbito internacional.

A origem deste novo Coronavírus divide opiniões em diversos cantos do mundo, sendo consensual, que geograficamente foi despoletado na China, concretamente, em Wuhan. Entretanto, existem opiniões de um lado, que defendem ser um vírus que apareceu de forma natural como quaisquer outros que afectam a humanidade. Estas opiniões salientam ainda que o vírus possui características biológicas que são inconsistentes com um vírus zoonótico de ocorrência natural.

Por outro, existem opiniões que defendem ser um vírus natural, mas desenvolvido no laboratório de forma artificial. Yan e seus colaboradores desenvolveram estudos que descrevem as evidências gnómicas, estruturais, médicas e da literatura que, quando consideradas em conjuntos, contradizem fortemente a teoria de origem natural. Os resultados destes estudos mostram que o SARS-Cov-2 deve ser um produto de laboratório, criado a partir do Coronavírus de morcego ZC45 e/ou ZXC21 como modelo ou estrutura. Estes autores reconhecem a censura que os resultados de estudo têm recebido por revistas científicas revisadas por pares, porém, mantêm-se firme nos resultados das suas investigações.

\footnotetext{
1 Pertencem a uma grande família de vírus que causam doenças que variam entre as gripes comuns e as doenças mais graves, como a síndrome respiratória do Oriente Médio (MERS-CoV), identificada em 2012 e a Síndrome Aguda Grave (SARS-CoV), identificada em 2002.
} 
Para Dr. Gkikas Magiorkinis ${ }^{2}$, Prof. Daniel Altmann³, o Dr. Andrew Preston $^{4}$, o Dr. Michel Head ${ }^{5}$, o artigo publicado por Yan e seus colaboradores não passou por uma revisão de pares, aliás, para estes pesquisadores este estudo não fornece nenhuma evidência de manipulação artificial, trata-se de uma teoria de conspiração que visa expor a corrupção, obstrução, ilegalidade, condenação excessiva, desumanidade generalizada nos sistemas políticos, jurídicos, empresarial e financeiro da China ${ }^{6}$.

A lógica dialéctica é uma possibilidade de compreensão da realidade como, essencialmente, contraditória e em permanente transformação (KONDER, 1981 apud PIRES, 1997), em contraposição à lógica formal, estática, que não aceita a contradição e o conflito (PIRES, 1997). Entretanto, a discussão acima desencadeada não constitui nenhum estranhamento na construção do conhecimento científico e na compreensão da realidade social, aliás, fornece-nos lentes para melhor produzirmos os nossos pontos de vistas. Portanto, o nosso estudo não pretende entrar nesse debate, porém, reconhece a existência de uma nova ordem mundial, conduzida pela China em paralelo com a Rússia, que se pretendem firmar como uma potência hegemónica, controlando a economia, reproduzindo o capital em substituição do ocidente.

Para Wache (2019), entre 1991 e 2009, o ocidente era o único polo de poder do sistema internacional que impunha a ordem mundial. Portanto, este autor salienta que a pretensão da China em firmar-se hegemónica colocou em guerra comercial entre os Estados Unidos e a China, desde 2017, na qual a China ascendeu ao estatuto de potência global, partilhando, deste modo, com os EUA o pódio do poder global.

Se se considerar a origem do coronavírus na vertente laboratorial, pode afirmar-se também que a disputa entre a China e os EUA pode não ser, simplesmente, comercial, mas sim, uma guerra biológica impulsionada pelo avanço tecnológico invejável desenvolvido pela China nos últimos anos, que

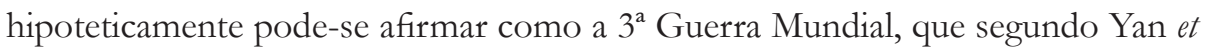
al (2020) já causou cerca de 910.000 mortes.

2 Professor assistente de Higiene e Epidemiologia e Coordenador Científico do Centro Nacional de referência para retrovírus da Universidade Nacional e Kapodistriana de Atenas;

3 Professor de Imunologia, Imperial College London;

$4 \quad$ Readaer in Microbial pathogenesis, University of Bath;

5 Pesquisador senior em Saude global, University of Southampton

6 https://www.sciencemediacentre.org/expert-reaction-to-preprint-entitled-unusual-features-ofthe-sars-cov-2-genome-suggesting-soph Sofistic-laboratory-modification-rather-than-natural- evolução-edelineação-de-seu-provável-s / 


\section{PARA MOÇAMBIQUE: UM NOVO ANORMAL OU UMA EDUCAÇÃO MELHOR?}

A educação em Moçambique resulta, em parte, da presença portuguesa e das escolhas políticas do partido no poder (FRELIMO). Portanto, a educação desenvolvida no período colonial era discriminatória, desenvolvia-se nas zonas urbanas e o objectivo era a exploração do homem pelo homem, isto é, formar mão-de-obra alfabetizada para atender o desenvolvimento das relações coloniais e garantir a posse e o domínio sobre o território colonial (BASÍLIO, 2010).

Após a independência, alcançada aos 25 de Junho de 1975, verificaramse avanços significativos no sector da educação, porém, este avanço foi posto em causa devido à Guerra Civil levada a cabo entre o Governo de Moçambique e a Renamo, marcando o seu fim, com a assinatura dos Acordos da Paz, em 4 de Outubro de 1992. A guerra civil, associada à seca e à estiagem que se vivia, desestabilizou o país, assim como, o sistema educativo o que condicionou ao triunfo do capitalismo econômico na história de Moçambique, materializado através de programas protagonizados pelos organismos multilaterais.

Atento à história da educação acima descrita, aduz-se que a educação sempre esteve associada a crises político-ideológicas, que a caracterizam como um campo contínuo e descontínuo ao mesmo tempo. Esta crise é extensiva ao sistema administrativo, no caso de rácio professor/aluno desconfigurado, infraestruturas precárias, segurança nas escolas inexistentes, mais tempo de permanência dos professores nas escolas talvez com salários baixos.

Agora, Moçambique enfrenta mais uma outra crise, que se impõe a conviver com o SARS-COV-2 e tudo indica que, contrariamente, à ideia inicial de uma curta duração da pandemia teremos que conviver com o vírus por muito tempo. Por isso existe a necessidade imprescindível de definir um novo normal que permita, simultaneamente, uma maior abertura ao funcionamento da sociedade e da economia do país e salvaguardar a Saúde Pública, evitando assim perda de vidas (ASSEMBLEIA DA REPÚBLICA, 2020).

Quase em todo canto do mundo recorre-se ao conceito do "novo normal" para designar uma nova filosofia de vida dos cidadãos com a origem da pandemia do Covid-19. Para nós, esta terminologia transborda consigo algum equívoco de aplicação no campo educacional, sobretudo, para os países sob dependência do ocidente. Por quê? Referia-se que antes da pandemia do Covid-19 a educação já estava em crise, o que pressupunha um modo de vida anormal. Por que vai ser um novo normal, enquanto, já havia uma filosofia de vida anormal? Por esta razão, a terminologia de novo normal, tão propalada no mundo inteiro, pode ter algumas limitações, no caso concreto de Moçambique e outros países que se encontram 
nas mesmas situações. Assim sendo, podia-se admitir a terminologia de "novo anormal" tendo em conta a ocorrência sucessiva e ao mesmo tempo paralela de dois grandes principais obstáculos (políticas neoliberais e o Covid-19) nos modus vivendi dos moçambicanos.

Considerando os estudos efectuados por Yan e seus associados, nota-se que a pandemia estimulada de forma artificial no laboratório, tinha um determinado objetivo, que, provavelmente, a China quisesse atingir seus contendores, principalmente, os EUA. Portanto, os seus efeitos espalharam-se quase pelo mundo todo, embora, em proporções inigualáveis com os principais alvos traçados pela China.

Moçambique é um país que não escapou da fúria dos beligerantes, porém, julgamos que fora da desumanização, corrupção provocada pela pandemia houve um grande alívio no sector da educação. Outrora, o rácio professor/aluno, no Ensino Secundário Geral, tinha-se em média entre 60 a 70 alunos por turma o que representava um grande desafio ao professor no processo de ensino e aprendizagem. Com esta pandemia o rácio reduziu a uma média de 20 a 25 alunos aliviando deste modo a superlotação das turmas, embora esta política não tenha resolvido cabalmente o problema do professor, isto é, este foi obrigado a dividir a turma que tradicionalmente tinha em duas turmas. Nestas condições o professor passa a trabalhar com duas turmas em dias alternados.

Antes da pandemia, havia falta de infraestrutura, principalmente, para o abastecimento de água pontével nas escolas públicas mesmo as que se encontravam nas zonas urbanas, sendo pior para as escolas das zonas rurais. Com a crise, o Governo de Moçambique redobrou esforços de modo a garantir o precioso líquido nas escolas, reforçando com outras medidas de biossegurança, higienização, factos a que não se tinha muita atenção antes da pandemia.

A revolução industrial e tecnológica impulsionou em parte a globalização. O mundo globalizado opera-se com o avanço das tecnologias de informação em que a educação é parte focal para materialização das TICs. O uso das TICs no sector da educação, apresenta-se bastante embrionário, sendo um desafio para os professores assim como para os alunos. Portanto, com a crise, houve a necessidade de desenvolvimento de aulas remotas, ou melhor virtuais em que professores, alunos e encarregados de educação foram impostos a saber operacionalizá-las de modo a continuar com o processo de ensino e aprendizagem. Esses e outros factores da crise aliviaram o sistema educacional rumo a uma educação desejada. 


\section{POSIÇÃO DO GOVERNO QUANTO AO SURTO DA PANDEMIA DO COVID-19}

A pandemia do Covid-19 desestruturou a vida pública de uma maneira profunda, colocando grandes desafios de adaptação no processo de ensino e aprendizagem. De modo a conter a rápida propagação do Coronavírus, o Conselho de Ministro criou a Comissão Técnico-Científica para a prevenção e resposta à pandemia do Covid-19, através da resolução n.o 20/2020, de 25 de Março, um órgão de consulta e assessoria técnica com profissionais de diversas especialidades, incluindo clínicas e de saúde pública, socioeconômicas, antropológicas e de comunicação social, com a função de assessorar o governo em matéria de resposta à pandemia.

Em seguida, através do Decreto Presidencial, n.o11/2020, de 30 de Março, ratificado pela Assembleia da República, pela Lei n.o 1/2020, de 31 de Março, decretou-se o Estado de Emergência por razões de calamidade pública em todo território nacional, com duração de 30 dias, começando às $0 \mathrm{~h}$ do dia $1 \mathrm{de}$ Abril de 2020 e com o término às 23 h do dia 30 de Abril.

Entretanto, dentre as medidas anunciadas pelo chefe do Estado, consta a suspensão das aulas em todos os estabelecimentos públicos e privados, desde o ensino pré-escolar até ao superior. Em resposta ao encerramento das escolas causadas pelo Covid-19, a UNESCO recomenda o recurso a programas de ensino a distância e plataformas de recursos educacionais abertos, de forma que as escolas e professores possam administrar as aulas de forma remota, diminuindo o impacto de encerramento da aprendizagem.

Quanto ao encerramento das escolas, sobretudo, das universidades, dividem-se opiniões de diferentes extractos sociais. Por um lado, uns apoiam o encerramento do ano, considerando ano zero, na tentativa de salvaguardar a saúde pública. Por outro, existem opiniões que consideram que as universidades sejam centro de produção e disseminação do conhecimento científico útil para a solução dos problemas sociais. Deste modo, encerrá-las representaria um perigo eminente na solução do controlo e propagação do Coronavírus.

Durante a defesa pública para ascensão à categoria de professor catedrático, o filósofo moçambicano, Severino Ngoenha, proferiu o seguinte:

Nós moçambicanos em frente ao Covid-19, como todos os países do mundo, esperamos uma vacina, mas ninguém espera que a vacina venha de nós, das nossas doutas instituições do Ensino Superior. Fechamos as universidades, único lugar que podemos produzir as nossas soluções ${ }^{7}$ (NGOENHA, 2020). 
Desta crítica, questionamos: Por que a vacina não pode vir de nós? Em nossa modesta opinião, Ngoenha denuncia a fragilidade das políticas educacionais do país, critica a qualidade e o fim das IES, denuncia que estas instituições não visam à solução dos problemas sociais que o país atravessa. Este critica o encerramento das aulas em universidades em resposta ao Coronavírus o que achamos também representar um certo risco para a educação se considerarmo-las como lugar de referência para a solução dos problemas do país. Acreditamos que se faz necessário que as universidades, enquanto instituição formadora de opinião e sistematizadora de conhecimento, estejam a par dos problemas imediatos que desafiam a comunidade, a fim de que possam ser parte de solução destes.

\section{DESAFIOS DA EDUCAÇÃO PERANTE A PANDEMIA DO COVID-19}

Manter alunos a aprender durante a pandemia do Covid-19 impõe desafios sem precedentes à educação. Por quê? Conforme introduziu-se o ensino virtual, as famosas aulas remotas, os professores foram encontrados de surpresa, assim como, os encarregados de educação. Sabe-se de antemão que a maioria dos moçambicanos vivem numa pobreza extrema o que lhes torna difícil custear o ensino virtual, ademais, estes encontram-se limitados no acesso à internt e na operacionalização das Tecnologias de Informação e Comunicação ${ }^{8}$ (TICs).

Para a eficácia do uso das TICs na sala de aula, surgiu no contexto internacional a estrutura conceitual designada por Technological Pedagogical Content Knowledge (TPACK). Tal estrutura, também conhecida como componentes, evidencia a necessidade de conhecimentos de conteúdos pedagógicos e tecnológicos e de todas suas possíveis relações, buscando demostrar algumas das características fundamentais para a actuação do docente com a utilização da tecnologia na sala de aula. O sucesso desta estrutura desafia ao provisionamento de infraestruturas em todas as instituições de ensino e a democratização de acesso às ferramentas tecnológicas, assim como, a dedicação total do professor.

A internet representa uma oportunidade, além do acesso à informação, de produção e divulgação de materiais próprios, como também de interação e aproximação seja dos conteúdos ou até mesmo das pessoas (DOS SANTOS, 2018). Em Mocambique constata-se limitações no acesso à internet vista em dois pontos antagónicos, mas que comungam o mesmo fim: (i) existe uma classe social, significativa, que vive em locais recondidos onde a rede de comunicação

8 São entendidas como um conjunto de diversas ferramentas para comunicar, disseminar, guardar e gerir informações (Dos Santos, 2018, p.23).

1472 - Rev. Bras. Polít. Adm. Educ. - v. 37, n. 3, p. 1463 - 1477, set./dez. 2021 
não flui, correctamente, devido à falta de energia; e (ii) mesmo as pessoas que se encontram, geopoliticamente, bem localizadas, onde a internet flui sem restrições de ordem técnica, constata-se que a maioria não reúne condições monetárias para o acesso, sobretudo, se olharmos a faixa estudantil. Estes fatos afectam não só o desenvolvimento das pesquisas com uma qualidade acentuada, mas também o desenvolvimento do processo pedagógico neste período da pandemia do Covid-19.

Para mitigar esse declínio, o governo tem investido no campo educacional, ainda que de forma tímida, em infraestruturas, biossegurança, principalmente nas cidades, sendo que nos distritos ainda constitui um desafio a alcançar. $O$ investimento no campo educacional não só se deve limitar em infraestruturas, biossegurança, mas também, em recursos humanos, no caso da formação permanente do professor, segundo às novas pedagogias de ensino, como também na tabela salarial do professor, tendo em conta que este precisa de trocar os seus instrumentos didáticos de ensino, alías, a concretização dessas aulas exige mais em termos de capacidade financeira, para permitir a comunicação permanente com os alunos. Desta feita, torna-se imprescindível que o governo negocie pacotes educativos tendo em vista a atualização do professor, sem descartar sua recompensa salarial.

Quanto às TICs, notam-se desafios que se destacam em duas linhas, principais: (i) uso de recursos tecnologicos (projector, videos, filmes, aulas em PowerPoint, moodle, google classroom, etc.) no processo de ensino e aprendizagem por parte do professor, assim como do aluno, sendo que, a maioria das aulas ministradas acontece via Whatsapp, que por sua vez, chega ao destinatário um pouco tarde, segundo a incapacidade financeira que estes apresentam em manter-se comunicável de forma regular; (ii) acesso aos recursos tecnológicos como dispositivos didáticos, isto significa que, professores e alunos não possuem recursos suficientes para abraçar o ensino híbrido como alternativa pedagógica viável, face à pandemia do Covid-19, alías, a maioria de alunos não dispõe do telfone celular, sendo que, dos que o têm, poucos possuem um telefone que tenha a capacidade de instalar o whtatsapp.

Portanto, o Estado é desafiado a flexibilizar políticas educativas que promovam e melhorem o sistema educacional em Moçambique, no âmbito da pandemia do Covid-19, através do pacto educativo. A este respeito, Ribas (2008) salienta que o novo profissional precisa interagir com a sociedade do conhecimento; para tal, é necessário repensar a educação quanto buscar os fundamentos para o uso dessas novas linguagens. Essas novas linguagens causam grande impacto na educação e determinam uma nova cultura na sociedade, novos valores e diferentes necessidades aos educadores, tanto no sistema presencial quanto a distância. 
A reabertura de escolas desafia cada vez mais ao Estado, em termos de políticas rodoviárias, isto é, os alunos são submetidos nos chapa $100^{\circ}$, autocarros superlotados, o que aumenta a probabilidade de transmissão do Coronavírus. Em nossa opinião, admitimos a possibilidade de criar-se um protocolo de transporte, de modo a se fiscalizar melhor a superlotação desses autocarros, o que ao mesmo tempo evitaria atrasos dos alunos, o que constitui um problema antigo. Portanto, para lograr-se este protocolo, é imperioso que haja um pacto educativo ${ }^{10}$ através de diálogo aberto com as famílias, os professores e a sociedade, a fim de realizar um trabalho colegial.

O pacto educativo não se trata de assumir um texto com os parceiros, mas de construir acordos capazes de assegurar alguma continuidade e suporte às políticas educativas, mobilizando a Sociedade Civil em torno da educação (BENAVENTE, 2004). Para a autora, o pacto educativo representa, por um lado, uma verdadeira revolução no modo de encarar a educação e promover a participação social de todos; por outro, responsabiliza a educação não só para o Estado, mas também, para todos actores sociais.

Acreditamos que um dos problemas que a educação moçambicana enfrenta é a falta de coesão e participação de todos extractos sociais na tomada de decisão sobre o tipo de educação que se pretende construir. $\mathrm{O}$ arrebatamento da pandemia mostrou a necessidade de encarar-se a educação como um sector multifuncional e que o seu sucesso depende, grandemente, da colaboração de todos.

\section{CONSIDERAÇÕES FINAIS}

A pandemia do Covid-19, por um lado, provocou desemprego de muitas famílias, colocou o comércio informal em crise, com a desumanização protagonizada pelo uso excessivo da força policial, chegando a desenvolver esquemas de sobrevivência (corrupção) entre os comerciantes informais e a polícia, o que compromete o Plano Quinquenal do Governo (2020-2024), recentemente aprovado, que tem como um dos objetivos a melhoria do bemestar, proporcionando deste modo a qualidade de vida dos moçambicanos.

\footnotetext{
9 Termo cunhado em Moçambique, no ambito da nativização do Português, para significar transporte público.

10 Terminologia usada por Papa Francisco para promover e reaviver o compromisso em prol e com gerações jovens, renovando a paixão por uma educação mais aberta e inclusiva, descrita por diálogo, construtivo e mútua cooperação.
} 
Por outro lado, concretamente, no campo educacional, a crise trouxe uma reforma necessária, sobretudo, no desembaraço do rácio professor/aluno, imperativo de aperfeiçoamento das TICs, redução de tempo de trabalho, iniciativas de criação de infraestruturas, higienização, biossegurança, componentes que não eram de grande relevo antes da pandemia. Com isto, não defendemos que o vírus permaneça connosco, aliás, o combate e o controlo da propagação do coronavírus não só cabe aos especialistas de educação, nem aos especialistas da saúde nem ao Estado, mas sim, a todos os estratos sociais, porém, sob o comando do Estado na flexibilização das políticas sociais, assim como, das políticas educativas. O Estado deve firmar um pacto educativo de modo a mitigar os efeitos da pandemia do Covid-19, com vista a colocar a Sociedade Civil e outros parceiros interessados na mitigação dos efeitos criados pela pandemia, assim como, os desafios que são enfrentados pelo sector da educação. A condução do processo do ensino por meio do uso das TICs mostra-se como um desafio para os professores e alunos em Moçambique.

\section{REFERÊNCIAS}

ASSEMBLEIA DA REPÚBLICA. IX Legislatura. Informação n.o 138/2020 de 30 de Julbo, Maputo, 2020.

BASÍLIO, G. O Estado e a Escola na Construção da Identidade Política Moçambicana, 2016,249, p. (Tese) Doutoramento em Educação: Currículo. Pontifícia Universidade Católica de São Paulo, 2010.

BENAVENTE, A. O Pacto Educativo para o futuro: Um instrumento estratégico para o desenvolvimento educacional em Portugal. Revista IberoAmericana de Educación. No.34, pp. 69-180, 2004.

BONDE, R. A. Políticas Públicas de Educação e Qualidade do Ensino em Moçambique. 2016. 168 p. (Dissertação de mestrado apresentada na Universidade Federal do Rio de Janeiro). Instituto de Economia, Brasil, 2016.

\section{DOS SANTOS, J. R. O Impacto das Novas Tecnologias da Informação e} Comunicação na Formação dos alunos do Ensino Medio de duas Escola da Rede Pública do Ensino de Estado de São Paulo, 2018, 147pps. Dissertação de mestrado em Ciencias da Educação apesentada na Univesrsidade Politecnica e Artistica de Praguay, 2018. 
LULUVA, S. Participação do Conselho de Escola na Gestão Escolar. Dissertação do mestrado apresentadana Faculdade de Educação. Universidade Eduardo Mondlane. Maputo, 2009.

PIRES, M.F.C. O Materialismo histórico-dialéctico e a Educação. InterfaceComunicação, Saúde e Educaşão, 1997.

GOVERNO DE MOÇAMBIQUE. Plano Nacional de Preparação e Resposta a Pandemia do Covid-19. Ministério da Saúde-Maputo, 2020.

RIBAS, D. A docência no Ensino Superior e as novas Tecnologias. Revista Electrónica Lato Sensu-Ano 3, no. 1, ISSN 1980-6116- Ciências Humanas, 2008.

WACHE, P.M. Geopolítica: Teorias, Doutrinas e Factores. Instituto Superior de Relações Internacionais-Maputo, 2019.

YAN, L.M.; KANG, Sh.; GUAN, G. \& HU, SH. Unusual Features of the SARSCoV-2 Genome Suggesting Sophisticated laboratory Modification Rather Than Natural Evolution and Delimitation of its probable Synthetic Route. New York, NY, USA. https://DOI: 10.5281/zenodo.4028829, 2020.

\footnotetext{
Fernando Andre Muzime

Professor do Ensino Secundário desde 2003 até 2018. Colabora com o Ensino Superior desde o ano de 2019, nas cadeiras de Metodologia de Investigação Científica, Metodologias de Projetos no Instituto Superior de Comunicação e Imagem de Moçambique (ISCIM) e na cadeira de Sociologia da Educação no Instituto São Tomás de Moçambique (ISTM). Doutorando em Educação, na linha de Políticas Educativas, na Faculdade de Educação da Universidade Eduardo Mondlane. Mestre em Administração e Gestão Escolar pela Universidade Pedagógica - Maxixe e licenciado em Ensino do Português pela Universidade Pedagógica - Maxixe. E-mail: fernandomuzime@gmail.com
} 


\section{Octavio Jose Zimbico}

Doutor em Educação, na linha de Instituições e Práticas Educativas Programa de Pós-graduação em Educação da Universidade do Estado do Rio de Janeiro (Proped/Uerj), Brasil (2016). Mestre em Administração e Gestão da Educação pela Faculdade de Educação da Universidade Eduardo Mondlane, em Maputo, Moçambique (2012). Licenciado em Pedagogia pela Faculdade de Ciências Pedagógicas da Universidade Pedagógica de Maputo, Moçambique (2005). Suas áreas de interesses incluem Políticas de Educação, Metodologia de Pesquisa em Educação, Gestão de Projetos Educativos, Avaliação de Programas e Projetos Educativos e Economia da Educação. E-mail: o.zimbico@gmail.com

Recebido em: 14/12/2020

Aprovado em: 08/06/2021 